\title{
Analysis of Delayed Postpolypectomy Bleeding in a Colorectal Clinic
}

\author{
Do Hyoung Kim, Seok Won Lim \\ Department of Surgery, Hang Clinic of Coloproctology, Seoul, Korea
}

Purpose: The colonoscopic polypectomy has become a valuable procedure for removing precursors of colorectal cancer, but some complications can be occurred. The most common complication after colonoscopic polypectomy is bleeding, which is reported to range from $1 \%$ to $6 \%$ and which can be immediate or delayed. Because the management of delayed postpolypectomy bleeding could be difficult, the use of preventive technique and reductions of risk factors are essential.

Methods: From January 2007 to December 2008, delayed hemorrhage occurred in 18 of the 1,841 polypectomy patients examined by one endoscopist. These cases were reviewed retrospectively for risk factors, pathologic findings, and treatment methods.

Results: Delayed bleeding occurred in 18/1,841 patients (0.95\%). The mean age was $55.9 \pm 10.9$ years, and the male-to-female ratio was $8: 1$. The most common site was the right colon (11 cases, $61.1 \%$ ), and the average polyp size was $9.2 \pm 2.8$ $\mathrm{mm}$. Delayed bleeding was identified from 1 to 5 days after resection (mean, $1.6 \pm 1.2$ days). The most common macroscopic type of polyp was a sessile polyp (10 cases, 55.6\%), and histologic finding was a tubular adenoma in 13 cases (72.2\%). Seventeen cases were treated with clipping for hemostasis and 1 case with epinephrine injection.

Conclusion: The right colon and a sessile polyp were associated with an increase in delayed postpolypectomy bleeding. Reducing risk factors and close observation were essential in high risk patients, and prompt management with hemoclips was effective.

\section{Keywords: Colonoscopy; Hemorrhage}

\section{INTRODUCTION}

With the improvement of equipment, a colonoscopic polypectomy is a procedure that can be performed safely, and it is becoming the standard for the treatment of polyps. Not only big polyps that are difficult to resect, but also superficial types, flat lesions, depressed mucosal lesions, early sessile colorectal cancer limited to the mucosa, and some submucosal tumors can be resected. However, various complications are associated with the proce-

Received: September 9, 2010 Accepted: October 19, 2010

Correspondence to: Seok Won Lim, M.D.

Department of Surgery, Hang Clinic of Coloproctology, 1643 Kwang-an

building, Sillim 8-dong, Gwanak-gu, Seoul 152-902, Korea

Tel: +82-2-855-7175, Fax: +82-2-855-7353

E-mail: hangclinic@yahoo.co.kr

Part of this article was represented at the 2010 ISUCRS in Seoul, Korea.

(C) 2011 The Korean Society of Coloproctology

This is an open-access article distributed under the terms of the Creative Commons Attribution NonCommercial License (http://creativecommons.org/licenses/by-nc/3.0) which permits unrestricted noncommercial use, distribution, and reproduction in any medium, provided the original work is properly cited. dure, and among them, the most common complication is hemorrhage, which has been reported in approximately $1-6 \%$ of all cases [1-3]. Hemorrhage is divided into immediate bleeding occurring during surgery and delayed bleeding developing between a few hours and 2 weeks after surgery. Immediate bleeding can be managed during endoscopic procedures by using endoscopic hemostasis immediately. Delayed bleeding is difficult to predict, and a massive hemorrhage may occur after discharge, in which case fatal problems may develop [3]. Based on a clinical analysis of delayed bleeding after an endoscopic polypectomy, we present safer endoscopic polypectomy methods. We also present a review of the literature.

\section{METHODS}

Among 1,841 patients who underwent a colonoscopic polypectomy at our hospital during the 2 years from January 2007 to December 2008, the clinical characteristics, histological differences and hemostatic methods of 18 patients in which delayed bleeding developed were analyzed. Colonoscopes $130 \mathrm{~cm}$ in length (CLV- 
E, Olympus Optical Co., Tokyo, Japan), were used. The polypectomy was performed by using the hot snaring resection method with electric galvanization using oval-type snares (Sub Micro, 1.0$\mathrm{cm}$ Loop, $2.3 \mathrm{~mm} \times 240 \mathrm{~cm}$, Telemed Systems, Inc., Hudson, MA, USA). The current at the time of resection was the cutting current (ERBE ICC200, ERBE Elektromedizin, Tubingen, Germany), and primarily, cutting currents were used. For cases of delayed bleeding, hemoclips (HX-600-090L, Aomori Olympus Co., Aomori, Japan) were used, or epinephrine was injected.

The medical records of 18 patients who developed delayed bleeding were analyzed retrospectively. For statistics, SPSS ver. 12.0 (SPSS Inc., Chicago, IL, USA) was used. For the univariate analysis, the $\mathrm{t}$-test and the $\chi^{2}$ test were used. Findings with $\mathrm{P}<0.05$ were considered to be statistically significant.

Table 1. Characteristics of delayed postpolypectomy bleeding patients

\begin{tabular}{lc}
\hline Characteristics & Patients $(\mathrm{n}=18)$ \\
\hline No. of cases/total & $18 / 1,841(0.95)$ \\
Bleeding day & $1.6 \pm 1.2(1-5)$ \\
Age $(\mathrm{yr})$ & $55.9 \pm 10.9(34-77)$ \\
Male:female & $16: 2$ \\
Comorbid disease & \\
$\quad$ Hypertension & $5(27.8)$ \\
Diabetes mellitus & $2(11.1)$ \\
Others & $3(16.7)$ \\
\hline
\end{tabular}

Values are presented as mean \pm SD (range) or number (\%).

Table 2. Presentation of delayed bleeding cases

\begin{tabular}{lcc}
\hline Characteristics & No. (\%) & P-value \\
\hline $\begin{array}{l}\text { Location of polyps } \\
\text { Ascending colon }\end{array}$ & $12(66.7)$ & \\
Transverse colon & $1(5.6)$ & \\
Descending colon & $4(22.2)$ & \\
Sigmoid colon & $1(5.6)$ & 0.154 \\
Size of polyps (mm) & & \\
$\geq 10$ & $6(33.3)$ & 0.007 \\
$<10$ & $12(66.7)$ & \\
Macroscopic type & & \\
Pedunculated & $1(5.6)$ & \\
Semipedunculated & $1(5.6)$ & 0.029 \\
Flat-elevated & $6(33.3)$ & \\
Sessile & $10(55.6)$ & \\
Pathologic type & & \\
Tubular adenoma & $13(72.2)$ & \\
Hyperplastic & $4(22.2)$ & \\
Inflammatory & $1(5.6)$ & \\
\hline
\end{tabular}

\section{RESULTS}

Among the 1,841 patients who underwent a colonoscopic polypectomy during the 2 years from January 2007 to December 2008, 18 developed delayed bleeding, and the incidence of hemorrhage was $0.95 \%$. The age at the onset of delayed bleeding ranged from 34 years to 77 years, and the mean age was $55.9 \pm 10.9$ years. The gender distribution was 16 males and 2 females, males being more numerous. As associated diseases, hypertension was noted in 5 cases $(27.8 \%)$, which was the most prevalent, and diabetes was detected in 2 cases (11.1\%). None of the patients took thrombolytic agents, together with hypertension agents or aspirin.

Hemorrhage developed between 1 day and 5 days after the polypectomy, day $1.6 \pm 1.2$ on average. Hemorrhage occurred after 1 day in 13 cases, which was the most prevalent, and after 2 days in 2 cases, after 4 days in 2 cases, and after 5 days in 1 case (Table 1 ). In regard to the location, 12 cases (66.7\%) involved the ascending colon, which was most prevalent $(\mathrm{P}=0.014)$, followed in order by 4 cases involving the descending colon, 1 case the sigmoid colon, and 1 case the transverse colon. The average size of the polyps was $9.2 \pm 2.8 \mathrm{~mm}, 6(33.3 \%)$ cases showing a maximal diameter larger than $10 \mathrm{~mm}$ and 12 cases (66.7\%) showing a maximal diameter smaller than that. For polyps larger than $10 \mathrm{~mm}$, size was not statistically associated with delayed bleeding $(\mathrm{P}=0.154)$.

Morphologically, pedunculated polyps were involved in 1 case

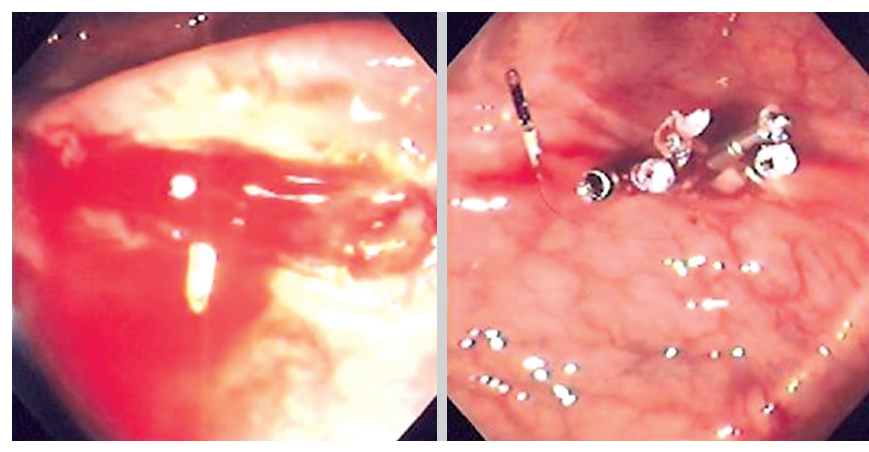

Fig. 1. Hemoclips applied at the delayed postpolypectomy bleeding site.

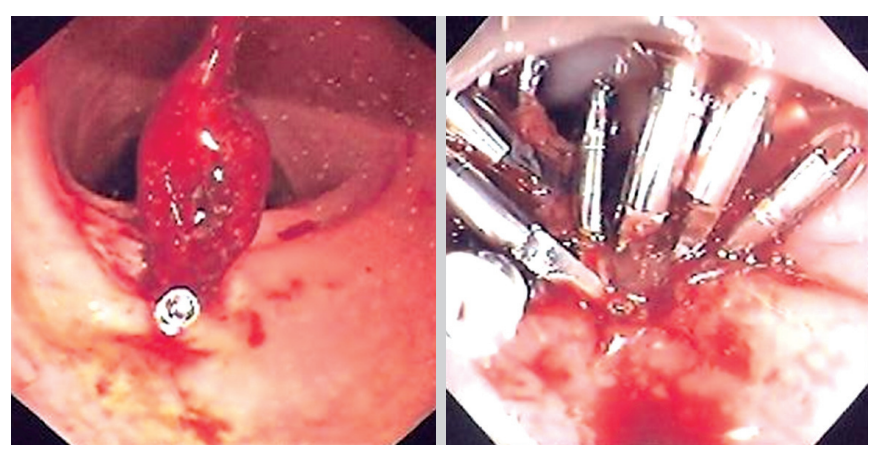

Fig. 2. Hemoclips reapplied at the delayed postpolypectomy rebleeding site. 
(5.6\%), semipedunculated polyps in 1 case (5.6\%), sessile polyps in 10 cases (55.6\%), and flat elevated polyps in 6 cases (33.3\%). The sessile-type polyp was the most prevalent $(\mathrm{P}=0.007)$. Histologically, an adenoma was noted in 13 cases $(72.2 \%)$, which was the most prevalent, hyperplastic polyps in 4 cases (22.2\%), and an inflammatory polyp in 1 case (5.6). Adenomas were significantly associated with delayed postpolypectomy bleeding $(\mathrm{P}=0.029)$ (Table 2).

In 17 cases, hemostasis was performed using hemoclips (Fig. 1), and in 1 case, epinephrine was injected. Despite hemostasis with hemoclips, re-bleeding developed in 2 cases, and hemostasis using hemoclips was performed again (Fig. 2). An average of $5.2 \pm$ 3.9 hemoclips was used, and in the two re-bleeding cases, 9 hemoclips and 17 homoclips, respectively, were used.

\section{DISCUSSION}

Complications that develop after a colonoscopic polypectomy are hemorrhage, perforation, postpolypectomy syndrome, etc. [3]. Among them, hemorrhage is the complication that develops most frequently. Early bleeding occurs immediately after resection, and delayed bleeding occurs from a few hours to a few days later in approximately $2 \%$ of all patients $[3,4]$.

For polyps smaller than $5 \mathrm{~mm}$ in size, a cold biopsy that removes polyps with forceps directly or a hot biopsy that removes polyps by electric galvanization is applied. The methods have been reported to leave residual lesions after resection, so the histological evaluation of the polyp is not easy [5]. Therefore for lesions smaller than $20 \mathrm{~mm}$, snares are frequently used. A snare resection is divided into cold snaring and hot snaring depending on electric galvanization $[6,7]$.

Hot snaring is a method that captures polyps by using a snare and galvanization. The method was performed and reported in 1969 by Shinya Hiromi et al. for the first time. It is the oldest and the most commonly performed method, and it has been applied to remove sessile polyps $0.5-1 \mathrm{~cm}$ in size or pedunculated polyps larger than $1 \mathrm{~cm}$ in size $[7,8]$. Among the oval type, crescent type, hexagonal type, spike type and other various types of snares, we have performed the hot snaring method with the oval type; after the injection of normal saline, polyps were snared and then galvanized using cutting currents.

Early bleeding occurs preferentially in cases in which polyps are resected by galvanization with excessive cutting currents without coagulation currents or monopolar cautery. The bleeding area can be assessed immediately, so it can be managed by forcipressure, clipping or submucosal epinephrine injection $[4,9]$. However, delayed bleeding, which develops from a few hours to a few days after surgery, manifests as continuous hematochezia, and in severe cases, ischemic shock may develop due to hemorrhage. The methods to predict or prevent delayed bleeding effectively are still controversial.

In several studies, delayed bleeding after a colonoscopic polyp- ectomy has been reported to occur preferentially after the resection of polyps that developed in the right large bowel in patients older than 65 years. It has been reported to occur as the shedding of coagulation necrotic tissues and the resolution of edema open the closed blood vessels again $[3,7,10]$. In regard to the development of delayed bleeding according to the location of the polyp, in our results, it developed mostly in the right large intestine, similar to other studies $(P=0.014)$. We speculate that due to the lumen being larger than other areas, the effect of compression hemostasis on managing hemorrhage caused by the exposure of blood vessels on the polypectomy surface was reduced, and submucosal blood vessels were exposed due to the relatively thin mucosa. Nonetheless, if the precise mechanisms are to be determined, more studies are required.

Delayed bleeding has been reported to be associated with the size of the polyp, and a size larger than $1 \mathrm{~cm}$ has been reported to be a risk factor. In our study, the size did not correlate to delayed bleeding $(\mathrm{P}=0.154)$, which is different from other studies. In sessile polyps, the incidence of delayed hemorrhage was shown to be high $(P=0.007)$, which could be associated not with the size of polyps, but with the fact that as the depth of the resection surface becomes deeper during the polypectomy, blood vessels in the submucosal area are exposed, becoming a risk factor for delayed bleeding.

In a colonoscopic polypectomy, delayed bleeding has been reported to occur in $0.7-2.5 \%$ of cases involving a snaring resection and in $0.4 \%$ of cases involving a hot biopsy. Even though in cases where pure coagulation currents are applied, the incidence of delayed bleeding is high, the association between the two is not clear $[11,12]$. In addition, the association of the experience level of surgeons with delayed bleeding has not been elucidated.

In regard to patient's factors, the use of warfarin increases the risk for delayed bleeding, and the incidence of delayed bleeding in hypertension cases is higher than it is in other cases [13]. Nevertheless, in our cases, all 18 cases who developed delayed bleeding had not taken aspirin or anticoagulant drugs routinely, and no association of hypertension with delayed bleeding was detected $(\mathrm{P}>$ 0.05).

The histological findings of polyps have been reported not to be associated with delayed bleeding. Nonetheless, in our cases, the presence of an adenoma was shown to be associated with delayed bleeding $(\mathrm{P}=0.029)$.

Hemorrhage developing after a polypectomy can be treated by endoscopic hemostasis, transfusion, interventional procedures, or surgery. Endoscopic treatments for hemorrhage are compression therapy with snares or forceps, injection of epinephrine or fibrous adhesives, mechanical ligation with hemoclips, etc., and thermal therapy such as argon plasma $[12,14]$. Among them, the most commonly used treatment is hemoclips, but that treatment has a shortcoming in that medical insurance does not cover its cost in Korea. Among various methods applied to prevent hemorrhage, the injection of epinephrine to the resection area of pedunculated 
polyps may prevent immediate bleeding effectively, but is not effective in preventing delayed hemorrhage [15]. In addition, it has been reported that hemoclips cannot prevent delayed bleeding, however, detachable snares can prevent immediate, as well as delayed, bleeding effectively [16].

In summary, the causes of delayed bleeding can be divided into the characteristics of the polyps, endoscopic resection techniques, and patient's characterfistics. In our cases, delayed bleeding occurred more frequently in cases involving sessile polyps, polyps in the right bowel, adenomas, and male patients. Since the incidence of such delayed bleeding is high within one week after a polypectomy, patients should rest for one week after the polypectomy and then visit an outpatient clinic. In addition, through a thorough understanding of various endoscopic hemostasis methods, when delayed bleeding occurs, it can be managed effectively.

In conclusion, the incidence of delayed bleeding was high in cases with sessile polyps or adenomas. To prevent delayed bleeding, various risk factors should be well understood. Also, after a polypectomy, the presence or absence of hemorrhage should be assessed carefully, and the possibility of delayed bleeding should be explained to the patients in advance. For the treatment of delayed bleeding, various hemostatic methods should be acquired so that when delayed bleeding occurs, it can be managed effectively.

\section{CONFLICT OF INTEREST}

No potential conflict of interest relevant to this article was reported.

\section{REFERENCES}

1. Rosen L, Bub DS, Reed JF 3rd, Nastasee SA. Hemorrhage following colonoscopic polypectomy. Dis Colon Rectum 1993;36:1126-31.

2. Dobrowolski S, Dobosz M, Babicki A, Głowacki J, Nałecz A. Blood supply of colorectal polyps correlates with risk of bleeding after colonoscopic polypectomy. Gastrointest Endosc 2006;63:1004-9.

3. Kim HS, Kim KU, Park WK, Cho KA, Hwang DY, Kang YW, et al. Delayed bleeding in a colonoscopic polypectomy: an experience with 5,236 polypectomies. J Korean Soc Coloproctol 2000; 16:462-8.
4. Parra-Blanco A, Kaminaga N, Kojima T, Endo Y, Tajiri A, Fujita R. Colonoscopic polypectomy with cutting current: is it safe? Gastrointest Endosc 2000;51:676-81.

5. Gilbert DA, DiMarino AJ, Jensen DM, Katon R, Kimmey MB, Laine LA, et al. Status evaluation: hot biopsy forceps. American Society for Gastrointestinal Endoscopy. Technology Assessment Committee. Gastrointest Endosc 1992;38:753-6.

6. Singh N, Harrison M, Rex DK. A survey of colonoscopic polypectomy practices among clinical gastroenterologists. Gastrointest Endosc 2004;60:414-8.

7. Tolliver KA, Rex DK. Colonoscopic polypectomy. Gastroenterol Clin North Am 2008;37:229-51.

8. Sivak MV. Polypectomy: looking back. Gastrointest Endosc 2004; 60:977-82.

9. Hui AJ, Wong RM, Ching JY, Hung LC, Chung SC, Sung JJ. Risk of colonoscopic polypectomy bleeding with anticoagulants and antiplatelet agents: analysis of 1657 cases. Gastrointest Endosc 2004;59:44-8.

10. Kim SM, Yun SY, Choi H, Kong JH, La SS. A case of delayed massive hemorrhage after endoscopic resecting a rectal carcinoid tumor. Korean J Gastrointest Endosc 2009;38:111-5.

11. Fatima H, Rex DK. Minimizing endoscopic complications: colonoscopic polypectomy. Gastrointest Endosc Clin N Am 2007;17: 145-56.

12. Baillie J. Postpolypectomy bleeding. Am J Gastroenterol 2007; 102:1151-3.

13. Friedland S, Soetikno R. Colonoscopy with polypectomy in anticoagulated patients. Gastrointest Endosc 2006;64:98-100.

14. Kouklakis G, Mpoumponaris A, Gatopoulou A, Efraimidou E, Manolas K, Lirantzopoulos N. Endoscopic resection of large pedunculated colonic polyps and risk of postpolypectomy bleeding with adrenaline injection versus endoloop and hemoclip: a prospective, randomized study. Surg Endosc 2009;23:2732-7.

15. Shioji K, Suzuki Y, Kobayashi M, Nakamura A, Azumaya M, Takeuchi M, et al. Prophylactic clip application does not decrease delayed bleeding after colonoscopic polypectomy. Gastrointest Endosc 2003;57:691-4.

16. Brandimarte G, Tursi A. Endoscopic snare excision of large pedunculated colorectal polyps: a new, safe, and effective technique. Endoscopy 2001;33:854-7. 